\title{
Recognition of apoptotic cells by macrophages activates the peroxisome proliferator-activated receptor- $\gamma$ and attenuates the oxidative burst
}

\author{
AM Johann ${ }^{1}$, A von Knethen ${ }^{1}$, D Lindemann ${ }^{2}$ and B Brüne ${ }^{\star, 1}$ \\ ${ }^{1}$ Institute of Biochemistry I, Faculty of Medicine, Johann Wolfgang Goethe- \\ University Frankfurt, Theodor-Stern-Kai 7, Frankfurt 60590, Germany \\ 2 Department of Virology, Technical University Dresden, Dresden 01307, \\ Germany \\ * Corresponding author: B Brüne, Johann Wolfgang Goethe-University, Institute \\ of Biochemistry I, Faculty of Medicine, Theodor-Stern-Kai 7, 60590 Frankfurt, \\ Germany. Tel: + 49696301 7423; Fax: + 49696301 4203; \\ E-mail: bruene@zbc.kgu.de
}

Received 13.7.05; revised 04.11.05; accepted 07.11.05; published online 09.12.05 Edited by B Zhivotovsky

\begin{abstract}
It is appreciated that phagocytosis of apoptotic cells (AC) is an immunological relevant process that shapes the proversus anti-inflammatory macrophage phenotype. It was our intention to study the respiratory burst, a prototype marker of macrophage activation, under the impact of AC. Following incubation of RAW264.7 macrophages with AC, we noticed attenuated production of reactive oxygen species (ROS) in response to PMA treatment, and observed a correlation between attenuated ROS formation and suppression of protein kinase $\mathrm{C} \alpha$ (PKC $\alpha$ ) activation. EMSA analysis demonstrated an immediate activation of peroxisome proliferatoractivated receptor- $\gamma$ (PPAR $\gamma$ ) following supplementation of $A C$ to macrophages. In macrophages carrying a dominantnegative PPAR $\gamma$ mutant, recognition of AC no longer suppressed PKC $\alpha$ activation, and the initial phase of ROS formation was largely restored. Interference with actin polymerization and transwell experiments suggest that recognition of $A C$ by macrophages suffices to attenuate the early phase of ROS formation that is attributed to PPAR $\gamma$ activation.

Cell Death and Differentiation (2006) 13, 1533-1540.

doi:10.1038/sj.cdd.4401832; published online 9 December 2005
\end{abstract}

Keywords: monocytes; macrophages; phagocytosis; inflammation; oxidative burst; PPAR $\gamma$

Abbreviations: AC, apoptotic cells; ROS, reactive oxygen species; PPAR $\gamma$, peroxisome proliferator-activated receptor- $\gamma$; $\mathrm{d} / \mathrm{n}$, dominant negative; $\mathrm{PKC} \alpha$, protein kinase $\mathrm{C} \alpha$

\section{Introduction}

Cells entering the route of programmed cell death are recognized by professional phagocytes. The uptake of dying cells before the cell membrane integrity is lost averts an inflammatory response in the surrounding tissue by preventing contact of neighboring cells with cellular constituents of dying cells. ${ }^{1}$ It became apparent that phagocytosis of apoptotic cells (AC) by macrophages is an immunologically relevant process that shapes the pro- versus anti-inflammatory cellular macrophage phenotype, provoking cell desensitization. This is characterized by the release of antiinflammatory cytokines such as TGF $\beta$ and the suppression of proinflammatory cytokine production. ${ }^{1}$ The engulfment of $A C$ by macrophages also attenuates $\mathrm{NO}$ production, as determined by decreased nitrite levels following LPS/IFN $\gamma$ stimulation. $^{2}$ Thus, clearance of AC must be considered as an immune regulatory process that is not species specific because major determinants for recognition are conserved between human and murine cells. ${ }^{3}$

Professional phagocytes produce reactive oxygen species (ROS) during phagocytosis of pathogens, which is considered a prototype marker of cell activation. The oxidative burst is triggered by a multicomponent NADPH oxidase protein complex. ${ }^{4}$ Stimulation of macrophages with the phorbol ester PMA provokes phosphorylation of $p 47^{\text {phox }}$, one of the cytosolic components of NADPH oxidase. ${ }^{5}$ Phosphorylation initiates translocation of a preformed $\mathrm{p} 47^{\text {phox }} / \mathrm{p} 67^{\text {phox }}$ complex to the cell membrane where it interacts with flavocytochrome $\mathrm{b}_{558}{ }^{6}$ to assemble the active NADPH oxidase. For human monocytes and RAW264.7 macrophages, it has been shown that the primary event, that is, phosphorylation of $\mathrm{p} 47^{\text {phox }}$, is facilitated by protein kinase $\mathrm{C} \alpha(\mathrm{PKC} \alpha){ }^{7,8}$ Recently, we demonstrated that downregulation of $\mathrm{PKC} \alpha$ or expression of a kinase-dead mutant attenuates the PMA-induced oxidative burst. ${ }^{9}$ However, the impact of $\mathrm{AC}$ on the oxidative burst remains unknown.

One candidate recognized for its ability to desensitize macrophages is the peroxisome proliferator-activated receptor- $\gamma$ (PPAR $\gamma),{ }^{10}$ belonging to the nuclear hormone receptor superfamily. ${ }^{11}$ Ligand binding activates PPAR $\gamma$, causes heterodimer formation with the retinoic $X$ receptor (RXR) and binding to peroxisome proliferator response elements (PPRE) in the promoter region of responsive genes. This is in contrast to the PPAR $\beta /$ RXR heterodimer that constitutively binds to the DNA. ${ }^{12}$ Besides transcriptional regulation via direct DNA binding, PPAR $\gamma$ attenuates gene expression by scavenging other transcription factors such as $\mathrm{NF}-\kappa \mathrm{B}^{13}$ or by hindering transcriptional cofactors to exert their costimulatory role. These effects are mediated by direct protein-protein interactions. $^{14}$

It was our intention to characterize the oxidative burst of macrophages following the uptake of $A C$. ROS formation was attenuated by recognition of $A C$ and correlated with the inability to activate PKC $\alpha$. Moreover, the initial but not the later phase of ROS suppression was reversed in macrophages carrying a dominant-negative mutant of PPAR $\gamma(d / n$ PPAR $\gamma)$, whereas $\mathrm{PKC} \alpha$-overexpressing cells could not be sensitized. 
Blocking phagocytosis with cytochalasin $D,{ }^{15}$ and transwell experiments indicated that binding of $A C$ to macrophages suffices in attenuating early cell activation. We conclude that recognition of apoptotic cell debris by macrophages is an immunologically relevant anti-inflammatory process that controls the macrophage oxidative burst.

\section{Results}

\section{AC attenuate nitrite- and ROS formation in macrophages}

First, we verified the anti-inflammatory effect of apoptotic Jurkat cells (AC) on RAW264.7 macrophages by following nitrite formation in the cell supernatant. Both AC and TGF $\beta$ attenuated LPS/INF $\gamma$-stimulated nitrite formation as previously described. ${ }^{2}$ Throughout the study, attenuated nitrite formation was followed as a marker indicating activation of anti-inflammatory pathways in macrophages. We then tested whether AC might affect ROS formation in RAW264.7 macrophages (Figure 1). With an initial experiment, we ruled out that coincubations of either apoptotic or necrotic Jurkat cells with macrophages produced ROS (Figure 1a and c). In contrast, stimulation of macrophages with PMA produced ROS-formation as detected by the rightward shift of the hydroethidine (HE) signal. Pre-incubating macrophages with AC for $1 \mathrm{~h}$ followed by PMA stimulation reduced ROS formation by roughly $50 \%$ (Figure $1 \mathrm{~b}$ ), whereas coincubations with necrotic cells did not impair ROS production (Figure 1d). This supports the finding of others that necrotic cells do not affect RAW264.7 cells. ${ }^{16}$ Exposing macrophages for $1 \mathrm{~h}$ to $5 \mathrm{ng} / \mathrm{ml}$ TGF $\beta$ neither provoked ROS formation on its own (Figure 1e), nor did TGF $\beta$ block the response towards PMA (Figure 1f). Statistical evaluation of these findings is shown in Figure 1g. It is interesting that $A C$ as well as TGF $\beta$ attenuated nitrite formation but TGF $\beta$ differed from $A C$ in the ability to suppress ROS formation at early times.

To exclude an impact of Jurkat cell protein on responses followed in macrophages we proved that $A C$ are washed off

Figure 1 ROS production in response to apoptotic or necrotic Jurkat cells and TGF $\beta$. ROS production in RAW264.7 macrophages was analyzed by flow cytometry using $3 \mu \mathrm{M} \mathrm{HE}$ as the redox-sensitive dye as described in Materials and Methods. Cells were stimulated with $1 \mu \mathrm{M}$ PMA (unfilled dark gray traces) or remained as controls (black traces). (a) AC were preincubated for $30 \mathrm{~min}$ (filled light gray), (b) AC were preincubated for $1 \mathrm{~h}$ with subsequent PMA addition (filled light gray), (c) Necrotic cells were preincubated for $30 \mathrm{~min}$ (filled light gray), (d) Necrotic cells were preincubated for $1 \mathrm{~h}$ with subsequent PMA addition (filled light gray), (e) $5 \mathrm{ng} / \mathrm{ml}$ TGF $\beta$ was preincubated for $30 \mathrm{~min}$ (filled light gray), (f) TGF $\beta$ was preincubated for $1 \mathrm{~h}$ with subsequent PMA addition (filled light gray). (g) Statistical evaluation of $(\mathbf{a}-\mathbf{f})$. The shift of the peak medians from untreated cells to PMA-treated cells was set as $100 \%$ activation and any inhibition was calculated proportionally. Data are the S.E.M. of at least three different experiments ( ${ }^{*} P \leq 0.05$ versus PMA-stimulated controls). (h-m) Successful removel of AC from RAW264.7 cells was confirmed by fluorescent microscopy. $A C$ were stained with Dil for 30 min before addition to macrophages. After $1 \mathrm{~h}, \mathrm{AC}$ were removed by washing two times with PBS. Pictures show RAW264.7 cells that remained untreated ( $h$; phase contrast; $\mathbf{i}$; red flourescence), exposed to AC (j; phase contrast; $\mathbf{k}$; red flourescence) and exposed to $\mathrm{AC}$ followed by washing two time with PBS (l; phase contrast; $\mathbf{m}$; red fluorescence). Data are representative of at least three individual experiments from macrophages before any further analysis in macrophages. We exposed RAW 264.7 cells for $1 \mathrm{~h}$ to 1,1'dioctadecyl-3,3,3',3'-tetramethyl-indocarbocyanine perchlorate (Dil) (red fluorescent dye)-stained AC, washed macrophages twice with PBS and analyzed macrophages by fluorescent microscopy (Figure 1h-m). Except for a few particles, taken up by phagocytosis, apoptotic Jurkat cells were removed by washing. Routinely using the washing
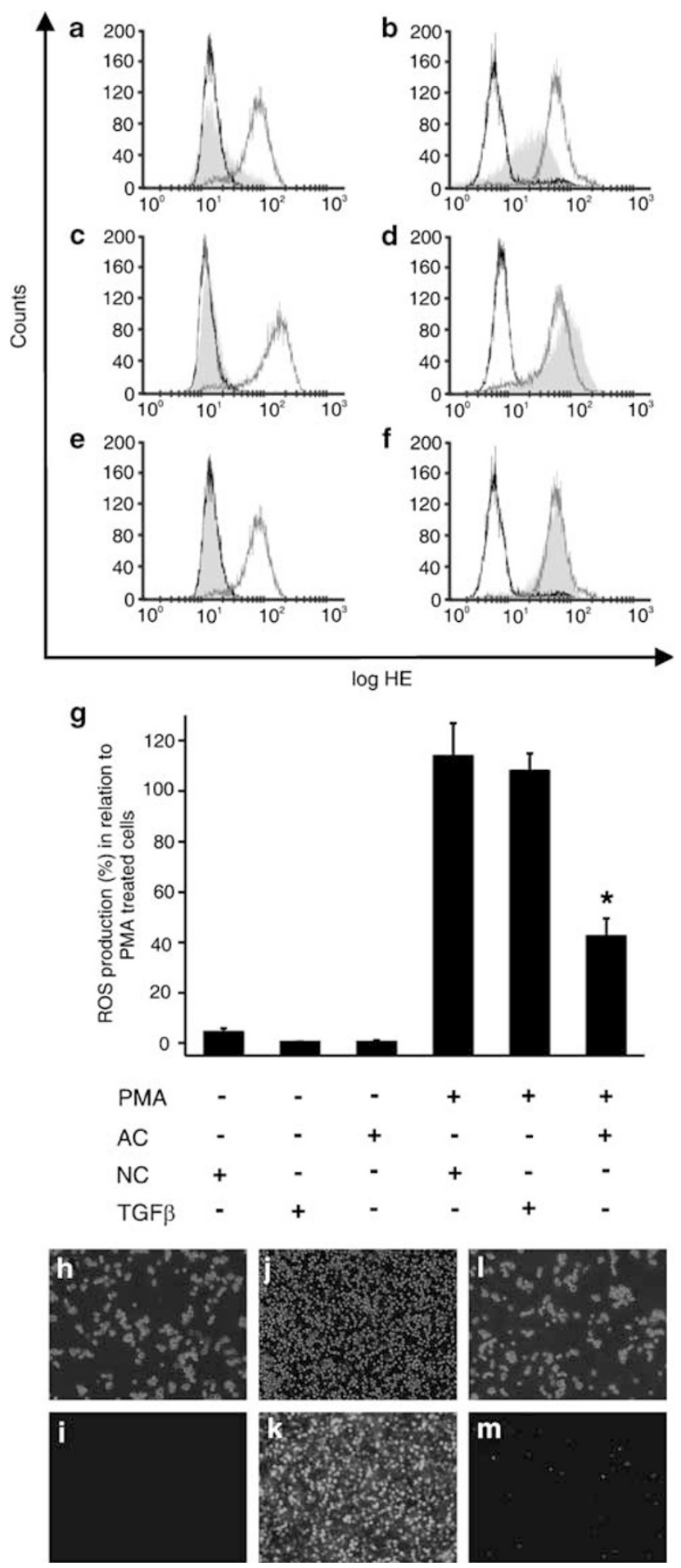
procedure in our experiments excludes the variations in the protein amount or ROS originating from contaminating AC.

To obtain supporting documentation that $A C$ attenuate ROS formation we followed $\mathrm{PKC} \alpha$ expression. Considering that subsequent to $\mathrm{PKC} \alpha$ activation by PMA, PKC $\alpha$ translocates to the membrane, a decrease of cytosolic $\mathrm{PKC} \alpha$ is indicative of its prior activation. Figure $2 \mathrm{a}$ shows protein expression of PKC $\alpha$ in RAW264.7 macrophages, which is not significantly altered when AC and macrophages are cocultured. As predicted, PMA addition for 1-6h provoked $\mathrm{PKC} \alpha$ activation. A cotreatment of macrophages with $\mathrm{AC}$ and PMA for $1 \mathrm{~h}$ completely blocked PKC $\alpha$ migration to the membrane. At $3 \mathrm{~h}, \mathrm{AC}$ attenuated PMA-induced $\mathrm{PKC} \alpha$ activation to a minor extent only, and the inhibitory effect was gone at $6 \mathrm{~h}$. Figure $2 \mathrm{~b}$ shows the statistical evaluation of PKC $\alpha$ levels during the first hour, when inhibition of $\mathrm{PKC} \alpha$ activation by $\mathrm{AC}$ was most prominent. Neither necrotic nor vital Jurkat cells influenced $\mathrm{PKC} \alpha$ activation.

To further prove that $\mathrm{PKC} \alpha$ activation and subsequent cytosol to membrane translocation is inhibited, we analyzed cytosolic versus the membrane fractions (Figure 2c). As expected, PMA provoked PKC $\alpha$ translocation to the membrane, whereas coincubations with $A C$ attenuated its translocation. To rule out that Jurkat protein may affect PKC $\alpha$ amounts detected by Western analysis we compared the amount of total protein recovered in samples with or without $\mathrm{AC}$, but failed to notice any difference. Thus, we rule out that Jurkat protein affects protein analysis in macrophages. We conclude that $A C$ suppress activation of $P K C \alpha$ and $R O S$ production in macrophages after $1 \mathrm{~h}$, but the effect vanishes after 3-6h.

\section{PPAR $\gamma$ modulates the oxidative burst in macrophages}

In order to obtain more information on potential signaling pathways induced by $A C$ in regulating the oxidative burst, we considered the established anti-inflammatory behavior of PPAR $\gamma$ by focusing on early events of macrophage activation occurring within $1 \mathrm{~h}$. Exposing RAW264.7 macrophages for $15-60 \mathrm{~min}$ to $\mathrm{AC}$, we noticed a transient activation of PPAR $\gamma$, which was most prominent at $15 \mathrm{~min}$ (Figure 3a). Thereafter, activation declined during the first hour, reaching nonstatistical values compared to resting macrophages after 45 min. Statistical analysis of EMSA data are shown in Figure 3b.

To address the role of PPAR $\gamma$ in the oxidative burst we eliminated PPAR $\gamma$ in RAW264.7 macrophages by retroviral transduction of a $d / n$ PPAR $\gamma$ mutant. Exposing macrophages carrying the $d / n$ PPAR $\gamma$ to $A C$ showed no activation of PPAR $\gamma$ (Figure 3a). In the following experiments, we used d/n PPAR $\gamma$ macrophages to analyze $\mathrm{PKC} \alpha$ expression (Figure $3 c$ ). Cytosolic expression of $\mathrm{PKC} \alpha$ remained unaffected when exposed to $A C$ but was activated when stimulated with PMA. This situation is comparable to the behavior of parent cells, documented in Figure $2 b$. However, parent and $d / n$ PPAR $\gamma$ macrophages behaved different when exposed to $A C$ and simultaneously stimulated with PMA. While translocation of $\mathrm{PKC} \alpha$ was completely prevented in parent cells (Figure $2 \mathrm{~b}$ ), activation of PKC $\alpha$ in $\mathrm{d} / \mathrm{n}$ PPAR $\gamma$ cells was significantly higher when treated with the combination AC/PMA compared to controls (Figure $3 c$ ). The statistical evaluation of these data is shown in Figure 3d.

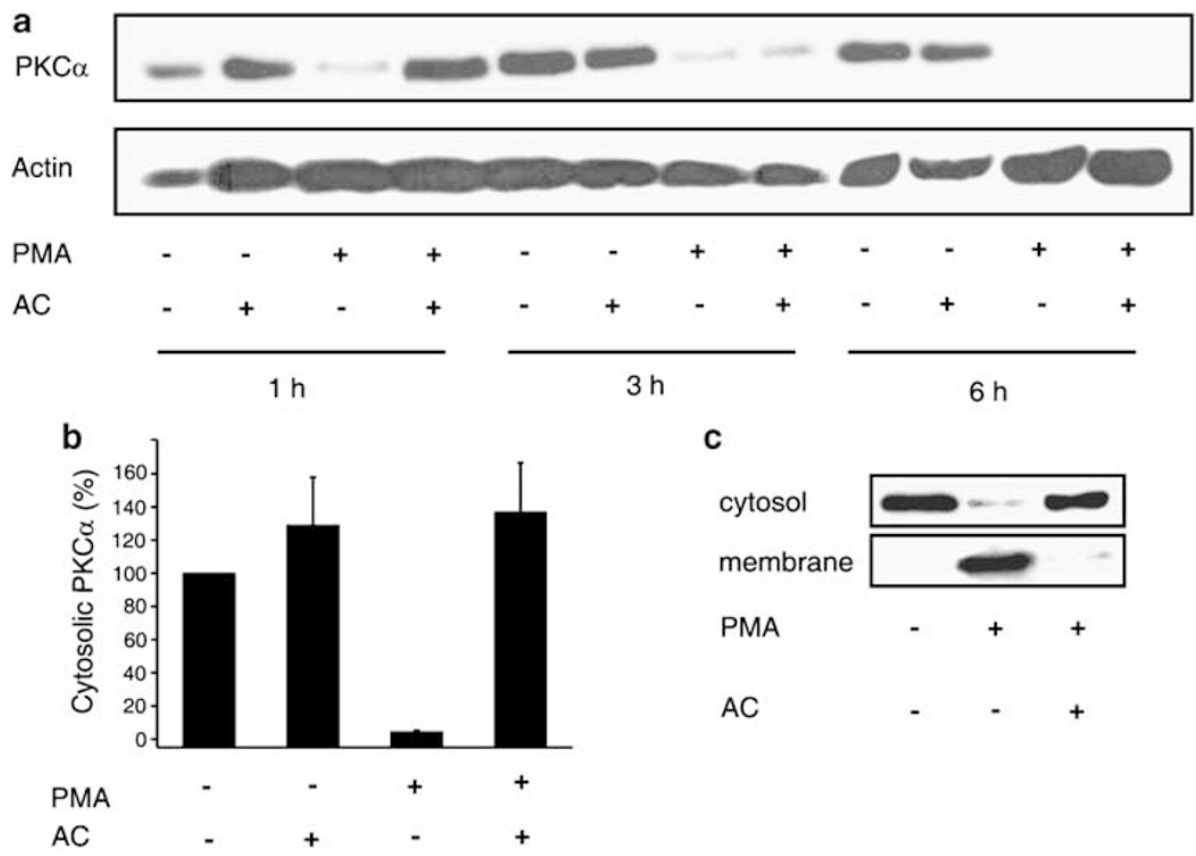

Figure 2 PKC $\alpha$ activation in response to PMA and apoptotic cells. (a) Cytosolic expression of PKC $\alpha$ and actin was determined in control RAW264.7 macrophages, following the addition of apoptotic Jurkat cells (AC), $100 \mathrm{nM}$ PMA, or a combination of PMA and AC. Treatments were for 1, 3 or $6 \mathrm{~h}$. (b) Statistical evaluation of Western blot data for $1 \mathrm{~h}$ treatments. (c) PKC $\alpha$ protein levels in the cytosolic versus membrane fractions were determined in control RAW264.7 macrophages, following the addition of $100 \mathrm{nM}$ PMA, or a combination of PMA and AC. Treatments were for $1 \mathrm{~h}$. For details see Materials and Methods. Data are the S.E.M. of at least three different experiments or are representative of at least three individual experiments 
a

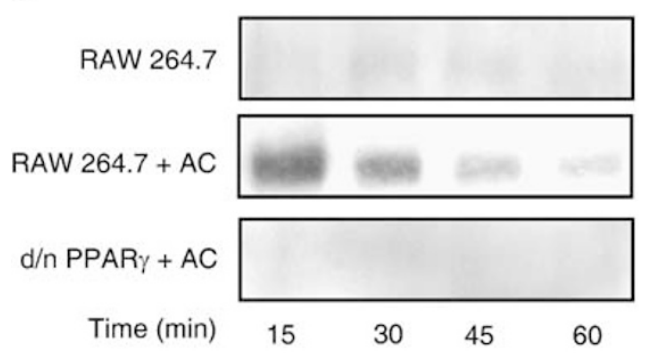

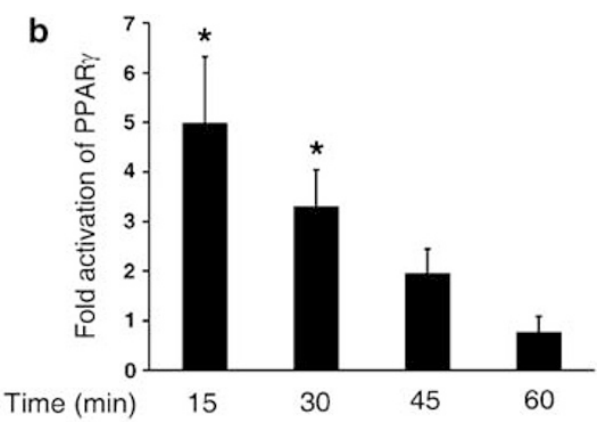

C

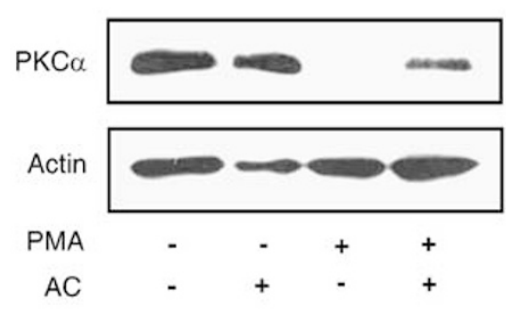

d

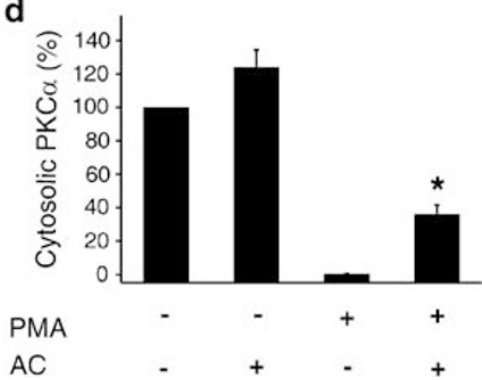

Figure 3 Activation of PPAR $\gamma$ in RAW264.7 macrophages. (a) EMSA analysis of PPAR $\gamma$ activation in untreated RAW264.7 macrophages (upper panel), in macrophages cocultured with $A C$ ( + AC; middle panel) and upon coculture of $A C$ with macrophages carrying a d/n PPAR $\gamma$ mutant (lower panel). Following stimulation for 15-60 min, EMSA analysis was performed as described under Materials and Methods. For controls (upper panel) cell stimulation was omitted. (b) Statistical evaluation of results obtained by EMSA analysis. Untreated controls are set as one. Data represent the S.E.M. of at least three individual experiments $\left({ }^{*} P \leq 0.05\right.$ versus unstimulated RAW264.7). (c) RAW264.7 macrophages carrying a d/n PPAR $\gamma$ mutant were exposed to AC and/or $100 \mathrm{nM}$ PMA for $1 \mathrm{~h}$ or remained as controls as indicated. Expression of PKC $\alpha$ and actin were followed by Western analysis. (d) Statistical analysis of the PKC $\alpha$ Western blots as shown in c. Data represent the S.E.M. of three individual experiments ( ${ }^{*} P \leq 0.05$ versus untreated controls)

Considering that PPAR $\gamma$ is necessary to attenuate PKC $\alpha$ activation, we now use $d / n$ PPAR $\gamma$ compared to parent macrophages to examine ROS-formation with $A C$ being preexposed (Figure 4). Adding AC to parent RAW264.7 macrophages attenuated PMA-evoked ROS formation. This was evident when AC were preincubated for $1 \mathrm{~h}$, with more pronounced inhibition seen at preincubation periods of 3 or $6 \mathrm{~h}$ (Figure $4 \mathrm{a}, \mathrm{c}$ and $\mathrm{e}$ ). Exposing $\mathrm{d} / \mathrm{n}$ PPAR $\gamma$ macrophages for $1 \mathrm{~h}$ to AC before PMA addition did not block ROS production at all (Figure 4b). The response was indistinguishable from the PMA effect but was different from the situation seen in parent cells (compare Figure $4 b$ and a). However, prolonging coincubation periods of $\mathrm{d} / \mathrm{n}$ PPAR $\gamma$ macrophages with AC reduced inhibition of ROS formation at a 3-h preincubation period, which became more pronounced after $6 \mathrm{~h}$ (Figure $4 \mathrm{~d}$ and $\mathrm{f}$ ). The statistical evaluation of these observations is presented in Figure 4g. Evidently, inhibition of ROS production in response to PMA is instantaneously attenuated in parent macrophages by the exposure to $\mathrm{AC}$, and increases from roughly $40 \%$ at $1 \mathrm{~h}$ to $60 \%$ at $6 \mathrm{~h}$. The situation in $\mathrm{d} / \mathrm{n}$ PPAR $\gamma$ macrophages is different. During early times of $A C$ addition, that is, at a 1-h preincubation period there is no inhibition while blockage of ROS formation became comparable to parent cells with a prolonged $A C$ exposure of $6 \mathrm{~h}$. This implies a biphasic inhibitory effect with only the early phase being PPAR $\gamma$ dependent. Therefore, PMA-evoked ROS formation in $d / n$ PPAR $\gamma$ macrophages upon recognition of $A C$ correlated at least in part with expression modulation, that is, activation of $\mathrm{PKC} \alpha$ as shown in Figure 3d.
To further prove an involvement of $\mathrm{PKC} \alpha$ in attenuating ROS production, we used PKC $\alpha$-overexpressing cells. ${ }^{9}$ Coincubations with AC before PMA activation left the oxidative burst unaltered, that is, comparable to PMA addition (Figure 4h) with statistical evaluation as shown in Figure 4i. This supports the idea that inhibition of ROS formation is a consequence of attenuated $\mathrm{PKC} \alpha$ activation.

\section{$A C$ recognition is sufficient to attenuate $\operatorname{PKC} \alpha$ activation by PMA}

To elucidate whether the impact of apoptotic Jurkat cells on macrophages requires cell-cell contacts we performed transwell experiments. In these experiments, $\mathrm{AC}$ and macrophages were separated by a permeable membrane that only allowed the passage of diffusible messengers. As shown in Figure $5 \mathrm{a}$, separation of $\mathrm{AC}$ and macrophages allowed activation of PKC $\alpha$ following PMA addition, which points to the requirement of direct cell-to-cell interactions, excluding the involvement of paracrine signaling. We then asked whether engulfment of $A C$ would be required to modulate $P K C \alpha$ activation or whether intercellular contacts would suffice. Experimentally, we used cytochalasin D, an inhibitor of actin polymerization, to block phagocytosis of AC (Figure $5 b$ ). As expected, cytochalasin $\mathrm{D}$ alone did not modulate cytosolic PKC $\alpha$ expression or PMA-induced PKC $\alpha$ activation. When treating macrophages with the combination of cytochalasin $\mathrm{D}$, AC and PMA, translocation of PKC $\alpha$ was suppressed. This indicates that phagocytosis of apoptotic material is not needed for AC to convey their signal. 


\section{Discussion}

It is appreciated that macrophages, following recognition/ elimination of $\mathrm{AC}$, acquire an altered inflammatory program when challenged with innate stimuli. ${ }^{17}$ This is reflected among other changes by decreased TNF $\alpha$ or NO formation ${ }^{1,2}$ but an increased production of $\mathrm{PGE}_{2}$ or TGF $\beta 1 .^{18}$ The ability of TGF $\beta$ and $A C$ to attenuate nitrite formation in macrophages was corroborated in our study, indicating the suitability of our
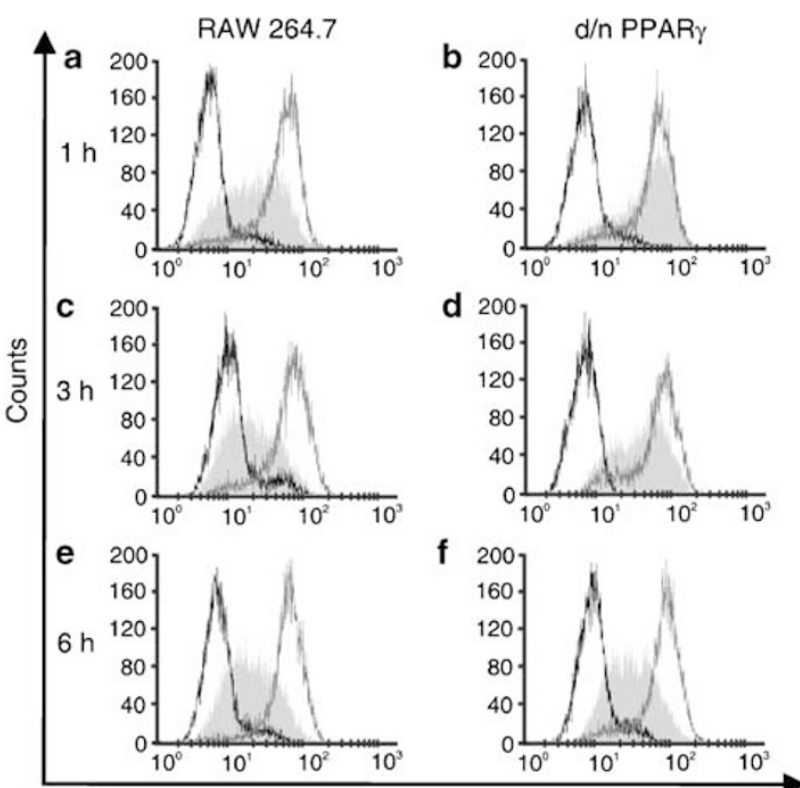

$\log \mathrm{HE}$

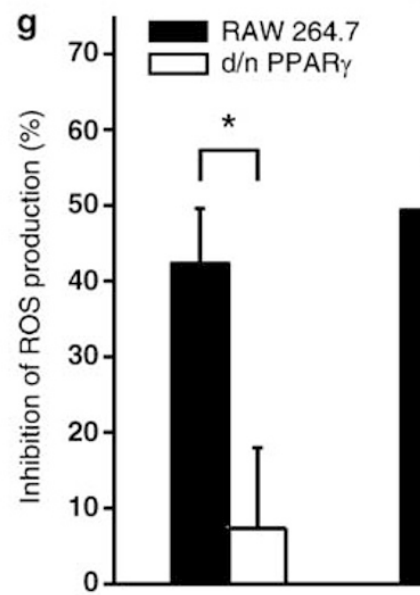

Time (h) $\quad 1$

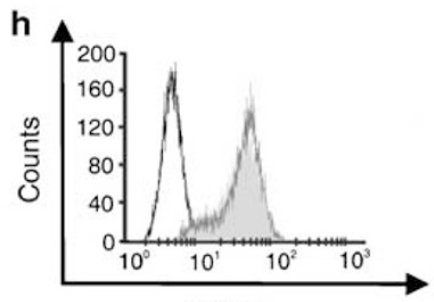

$\log \mathrm{HE}$

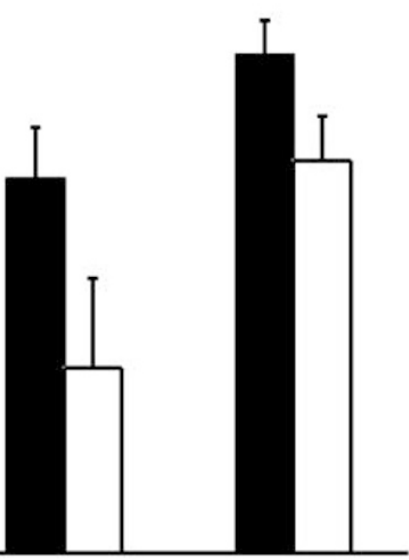

3

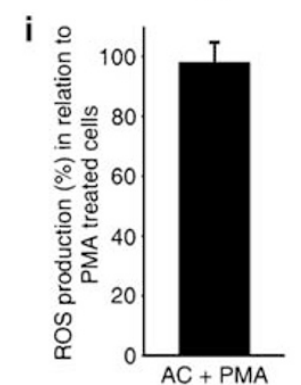

test system. For most experiments, we used a macrophage$\mathrm{AC}$ coculture period of $1 \mathrm{~h}$. During this period, the population of Jurkat cells exclusively revealed apoptotic markers, implying that alterations seen in macrophages are associated with the impact of apoptotic rather than necrotic or viable cells.

ROS formation is an early marker of macrophage activation, and is important in bactericidal activity. Activation of NADPH oxidase requires $\mathrm{PKC} \alpha$ activation in order to facilitate phosphorylation of $\mathrm{p} 47^{\text {phox }}$ and thus assembly of the functional oxidase complex. ${ }^{5}$ Inherent to $\mathrm{PKC} \alpha$ activation one finds protein translocation to the plasma membrane, which is a correlative marker for kinase activation. ${ }^{19}$ Our data extends existing knowledge on the ability of $A C$ to modulate the macrophage behavior by attenuating PMA-evoked ROS formation in RAW264.7 cells. $^{20}$ In our experiments, AC attenuated ROS generation and preserved cytosolic PKC $\alpha$

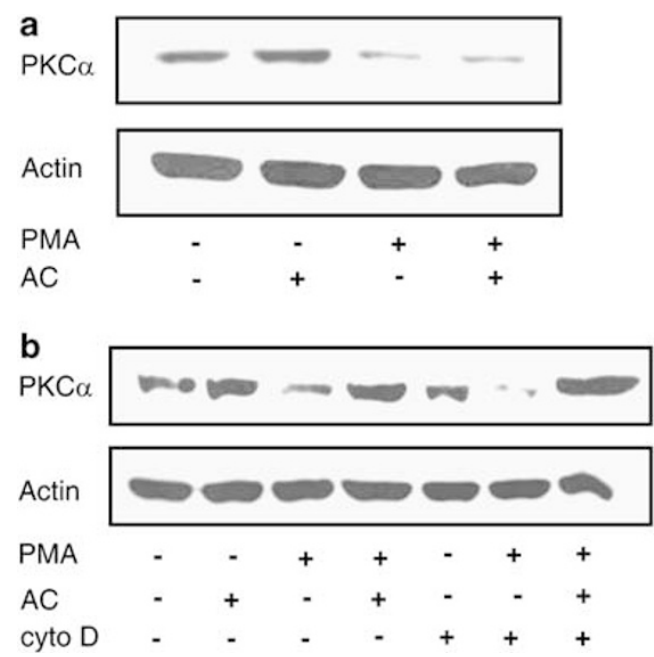

Figure 5 Roles of phagocytosis and paracrine signaling in modulating $\mathrm{PKC} \alpha$ activation. (a) A transwell set up was used to separate apoptotic Jurkat cells from macrophages. Not allowing a direct cell-cell contact, macrophages were exposed to $\mathrm{AC}$ and/or $100 \mathrm{nM}$ PMA for $1 \mathrm{~h}$ or remained as controls. Cytosolic expression of PKC $\alpha$ and actin were followed by Western analysis. (b) RAW264.7 macrophages were exposed to $A C, 2 \mu \mathrm{M}$ cytochalasin $D$ (cyto D) and/or $100 \mathrm{nM}$ PMA for $1 \mathrm{~h}$ or remained as controls as indicated. Cyto $\mathrm{D}$ was preincubated for $45 \mathrm{~min}$. Translocation of PKC $\alpha$ was determined as indicated under Materials and Methods. Blots are representative for three individual experiments

Figure 4 ROS production in response to AC in RAW264.7, d/n PPAR $\gamma$ or PKC $\alpha$-overexpressing macrophages. ROS production in parent and $\mathrm{d} / \mathrm{n} \mathrm{PPAR} \gamma$ transduced RAW264.7 macrophages was analyzed by flow cytometry using $3 \mu \mathrm{M}$ $\mathrm{HE}$ as the redox-sensitive dye. Cells were stimulated with $1 \mu \mathrm{M}$ PMA (unfilled dark gray traces) or remained as controls (black traces). Apoptotic cells were added for 1,3 or $6 \mathrm{~h}$ before PMA addition. (a-b) AC were preincubated for $1 \mathrm{~h}$ prior to PMA addition (filled light gray), (c-d) AC were preincubated for $3 \mathrm{~h}$ before PMA addition (filled light gray), (e-f): AC were preincubated for $6 \mathrm{~h}$ before PMA addition (filled light gray). (g) Statistical examination of results presented in a-f. The shift of the peak medians from untreated cells to PMA-treated cells was set as $100 \%$ activation, and any inhibition was calculated proportionally. (h) ROS production in PKC $\alpha$-overexpressing RAW264.7 macrophages was analyzed by flow cytometry using $3 \mu \mathrm{M} \mathrm{HE}$. Cells were stimulated with $1 \mu \mathrm{M}$ PMA (unfilled dark gray traces) or remained as controls (black traces). AC were preincubated for $1 \mathrm{~h}$ before PMA addition (filled light gray). (i) Statistical evaluation of data shown in $\mathbf{h}$. Data represent the S.E.M. of at least four individual experiments $\left({ }^{\star} P \leq 0.05\right.$ versus $\left.\mathrm{RAW} 264.7\right)$ 
expression, indicating that the kinase was not activated by PMA. This suggests that the primary step in NADPH oxidase activation, that is, $\mathrm{PKC} \alpha$ activation, was inhibited. Interestingly, ROS suppression was not shared by TGF $\beta$ signaling, implying that different signaling pathways affect inhibition of NO versus ROS formation. Although TGF $\beta$ has been proposed as an important mediator of $A C$ in reprogramming macrophages, ${ }^{18}$ other studies suggested that TGF $\beta$ does not affect the initial anti-inflammatory response following $A C$ recognition such as modulating NF- $\kappa$ B activity. ${ }^{15}$ This is consistent with our observation that early regulation of ROS production is TGF $\beta$ independent.

Recent information implies a role for PPAR $\gamma$ in inflammation control. ${ }^{10}$ Activation of PPAR $\gamma$ can be achieved by fatty acid metabolites, including those of the arachidonic acid cascade. $^{12}$ Immunosuppressive functions are largely mediated through the ability of PPAR $\gamma$ to transrepress the activities of transcription factors such as NF- $\kappa \mathrm{B}$, STATs or NFAT. ${ }^{10}$ One may assume that recognition of $A C$ generates lipid-based signals needed for PPAR $\gamma$ activation. This hypothesis is supported by the notion that uptake of oxidized lipoproteins (oxLDL), which is facilitated at least in part by receptors also involved in the uptake of AC, that is, CD36, promotes PPAR $\gamma$ activation. ${ }^{21}$ There is evidence that oxidation of lipid components, for example, phosphatidylserine, at the outer membrane of $A C$ is required as a recognition signal that allows phagocytosis of $A C{ }^{22}$ One can speculate whether oxidized lipid components of $A C$, in some analogy to oxidized lipid components of oxLDL, account for PPAR $\gamma$ activation and whether signals are transmitted via CD36. Furthermore, AC have been shown to release phospholipids such as lysophosphatidylcholine, which influence the macrophage behavior. ${ }^{23}$ Recently, it was shown that oxidized eicosanoids ${ }^{24}$ or lysophosphatidic $\mathrm{acid}^{25}$ may provoke PPAR $\gamma$ activation, and thus represent possible PPAR $\gamma$ activation signals.

Our study shows a rapid and transient activation of PPAR $\gamma$ by $A C$ within $1 \mathrm{~h}$, which is correlated to attenuated ROS production and preserved $\mathrm{PKC} \alpha$ expression that otherwise translocates to the membrane because of PMA addition. A direct role of PPAR $\gamma$ was proven in $d / n$ PPAR $\gamma$-expressing macrophages. These cells, despite $A C$ treatment, generated ROS and revealed decreased cytosolic expression of PKC $\alpha$ in response to PMA. Interestingly, it has been reported that rosiglitazone, known to activate PPAR $\gamma$, partially inhibits oxLDL-induced PKC activity ${ }^{26}$ and blocks $\mathrm{PKC} \delta$ signaling. ${ }^{27}$ Furthermore, the absence of ROS inhibition in PKC $\alpha$-overexpressing cells supports the central role of $\mathrm{PKC} \alpha$ in regulating the oxidative burst. Although mechanistic insights to explain how PPAR $\gamma$ might block $\operatorname{PKC} \alpha$ activation and subsequent NADPH oxidase assembly await clarification, (in)direct protein-protein interactions of $\mathrm{PKC} \alpha$ with PPAR $\gamma$ and/or the degree of phosphorylation of $\mathrm{PKC} \alpha$ by either attenuating kinases or stimulating phosphatases appear testable approaches. Direct interactions of PPARs with other cytosolic proteins has been shown, ${ }^{28}$ which supports the assumption that a similar mechanism may apply to the interaction of PKC $\alpha$ and PPAR $\gamma$. Besides short-term activation as seen in this study, PPAR $\gamma$ is also involved in long-term regulation of ROS formation, ${ }^{29}$ and thus accounts for an alternative mechanism to regulate ROS production at later time points. Again, this hypothesis will be tested in the future. The controversy about whether RAW264.7 macrophages indeed express PPAR $\gamma$ has been settled by showing that these cells express PPAR $\gamma$ mRNA $^{30}$ and protein ${ }^{31}$ as well as its activation in response to LPS/IFN $\gamma{ }^{32}$ Our data on EMSA analysis, reporter activity and elimination of PPAR $\gamma$ effects by transduction of a $d / n$ PPAR $\gamma$ mutant corroborated these findings.

Following suggestions that soluble factors released from AC may influence macrophages, ${ }^{17}$ we performed transwell experiments which ruled out the involvement of paracine signaling. Moreover, experiments with cytochalasin D suggested that cell-cell contacts rather than phagocytosis of apoptotic material suffices in attenuating ROS formation. This supports findings by others showing that binding of $A C$ to macrophages was sufficient in exerting anti-inflammatory effects. ${ }^{15}$ The finding that ROS production is not completely inhibited although PKC $\alpha$ is apparently translocated at later time points suggests that $\mathrm{PKC} \alpha$ may not be the exclusive factor responsible for the PMA-induced oxidative burst.

In summary, our study shows that binding of $A C$ to murine macrophages attenuates the oxidative burst via an early PPAR $\gamma$-dependent inhibition of PKC $\alpha$ activation.

\section{Materials and Methods}

\section{Materials}

PMA, staurosporine, cytochalasin D and LPS were purchased from Sigma (Deisenhofen, Germany). HE and Dil were obtained from Molecular Probes (Leiden, The Netherlands). Murine $\mathrm{rlFN} \gamma_{\gamma}$ and the alkaline phosphatase-labeled antidigoxigenin (DIG) antibody were from Roche Diagnostics (Mannheim, Germany). Culture supplements and FCS were ordered from Biochrom (Berlin, Germany). Oligonucleotides were bought from Eurogentec (Seraing, Belgium). Antiactin antibody was purchased from Amersham Bioscience (Freiburg, Germany). Mouse anti-PKC $\alpha$ and TGF $\beta$ were obtained from BD Biosciences (Heidelberg, Germany). All chemicals were of the highest grade of purity and were commercially available.

\section{Vector construction}

To suppress PPAR $\gamma$ signaling in RAW264.7. macrophages, a PPAR $\mathrm{d} / \mathrm{n}$ mutant (PPAR $\gamma$-AF2), kindly provided by Prof. Chatterjee, Department of Medicine, University of Cambridge, UK, was used. There are two mutations in the AF2 domain (Leu468Ala/Glu471Ala), thus impairing ligand binding and concomitant ligand-dependent PPAR $\gamma$ activation. ${ }^{33}$ The mutant was subcloned into a retroviral vector system to allow efficient gene transfer and genomic integration of the gene. Therefore, it was transferred into the Hpal site of the multicloning site of the retroviral pLXIN vector (Clontech, BD Biosciences, Heidelberg, Germany). Primers were designed to generate a DNA fragment, containing the PPAR $\gamma-A F 2$ sequence. The sequences of the primers were as follows $5^{\prime}>35^{\prime}$-ATG ACC ATG GTT GAC ACA GAG ATC G-3', $T_{\mathrm{A}}=62^{\circ} \mathrm{C} ; 3^{\prime}>5^{\prime} 5^{\prime}$-GTA CAA GTC CTT GTA GAT CGC CTG CAG AGC- $3^{\prime}, T_{\mathrm{A}}=62^{\circ} \mathrm{C}$. By PCR we generated a $1490 \mathrm{bp}$ fragment, which was run on agarose gels, eluted and ligated into the Hpal-opened pLXIN vector. Correct orientation was verified by restriction analyses followed sequencing. 


\section{Retroviral transduction}

Retroviral infection of RAW264.7 macrophages was performed essentially as described. ${ }^{34}$ Briefly, transient transfection of packaging plasmids encoding the vesicular stomatitis virus glycoprotein $G^{35}$ and the MLV-gagpol genes ${ }^{36}$ together with the retroviral vector pLXIN-PPAR $\gamma-A F 2$ was carried out in 293T cells. Target cells were then incubated for $24 \mathrm{~h}$ with the infectious supernatant containing $8 \mu \mathrm{g} / \mathrm{ml}$ polybrene. Positive clones $(\mathrm{d} / \mathrm{n}$ PPAR $\gamma$ ) were verified by PPAR $\gamma$ mutant-specific PCR of genomic DNA and reporter assay. PKC $\alpha$-overexpressing RAW 264.7 macrophages were used as described recently. ${ }^{9}$

\section{Cell culture}

The mouse monocyte/macrophage cell line RAW264.7 and the human T-cell line Jurkat were maintained in RPMI 1640 supplemented with $100 \mathrm{U} /$ $\mathrm{ml}$ penicillin, $100 \mu \mathrm{g} / \mathrm{ml}$ streptomycin and $10 \%$ heat-inactivated FCS. For induction of apoptosis, a medium without FCS was used. For transwell experiments, we used the Falcon ${ }^{\mathrm{TM}}$ Cell culture insert System (BD Labware, Heidelberg, Germany) with a $1.0 \mu \mathrm{m}$ PET insert.

\section{Generation of apoptotic and necrotic cells}

To generate $A C$ an appropriate amount of Jurkat cells was seeded in $10 \mathrm{~cm}$ dishes in RPMI 1640 without FCS, supplemented with $100 \mathrm{U} / \mathrm{ml}$ penicillin and $100 \mu \mathrm{g} / \mathrm{ml}$ streptomycin. Cells were incubated for $3 \mathrm{~h}$ with $0.5 \mu \mathrm{g} / \mathrm{ml}$ staurosporine and afterwards washed twice with medium. Necrotic cells were generated by heating an appropriate number of Jurkat cells at $55^{\circ} \mathrm{C}$ for $25 \mathrm{~min}^{15} \mathrm{In}$ all experiments, the ratio of apoptotic or necrotic cells to macrophages was kept at a ratio of $5: 1$. For all Western blots, EMSA analysis and flow cytometry experiments, apoptotic Jurkat cells were removed by washing two times with PBS. Cell death was confirmed by flow cytometry, using annexin V-FITC/PI labeling (Immunotech, Marseille, France).

\section{Western blot analysis}

PKC $\alpha$ Western blot analysis was carried out as described before ${ }^{9}$ with the modification of using $60 \mu \mathrm{g}$ protein. Anti-PKC $\alpha$ was used at a ratio of $1: 1000$ and HRP-labeled goat anti-rabbit secondary antibody was used at a dilution of $1: 2000$.

\section{EMSA}

An established EMSA method with minor modifications was used. ${ }^{37}$ Nuclear protein $(20 \mu \mathrm{g})$ was incubated for $20 \mathrm{~min}$ at room temperature with $2 \mu \mathrm{g}$ poly(dl-dC) from Pharmacia, $2.5 \mu$ l buffer D (20 mM HEPES/KOH, $20 \%$ glycerol, $100 \mathrm{mM} \mathrm{KCl}, 0.5 \mathrm{mM}$ EDTA, 0.25\% Nonidet P-40, $2 \mathrm{mM}$ DTT, $0.5 \mathrm{mM}$ PMSF, pH 7.9), $5 \mu$ l buffer F (20\% Ficoll-400, $100 \mathrm{mM}$ HEPES/KOH, $300 \mathrm{mM} \mathrm{KCl}, 10 \mathrm{mM}$ DTT, $0.5 \mathrm{mM}$ PMSF, pH 7.9) and $200 \mathrm{fmol} 5$-DIG-labeled oligonucleotides in a final volume of $25 \mu \mathrm{l}$. DNAprotein complexes were resolved at $80 \mathrm{~V}$ using a taurine-buffered native $6 \%$ polyacrylamide gel, blotted onto positively charged nylon membranes (Nytran Supercharge, Schleicher and Schuell, Dassel, Germany) and crosslinked with $4 \mathrm{~J} / \mathrm{cm}^{2}$ on a UV transilluminator. DNA was detected using an alkaline phosphatase-labeled anti-DIG antibody and visualized using the substrate CSPD according to the manufacturer's protocol. Oligonucleotides with the consensus PPRE site highlighted (bold letters) were used $^{38}$ : $5^{\prime}$-GGT AAA GGT CAA AGG TCA AT-3'; 3'-A TTT CCA GTT TCC AGT TAG CCG-5'.

\section{Flow cytometry of oxygen radical production (HE assay)}

RAW264.7 cells were seeded in $3 \mathrm{~cm}$ plates at a density of $1 \times 10^{5}$ cells/ plate $24 \mathrm{~h}$ before the experiment. After 1,3 or $6 \mathrm{~h}$ of preincubation with apoptotic Jurkat cells, the medium and $A C$ were removed by washing two times with $1 \mathrm{ml}$ PBS. Macrophages were then suspended in $1 \mathrm{ml} \mathrm{PBS}$ and incubated for 30 min with $1 \mu \mathrm{M}$ PMA. Thereafter, $3 \mu \mathrm{M} \mathrm{HE}$ was added and incubations went on for $30 \mathrm{~min}$. Flow cytometry analysis was performed using a FACSCalibur flow cytometer (BD Biosciences, Heidelberg, Germany) by means of the CellQuestPro software. HE was measured at $630 \mathrm{~nm}$ emission (FL3). Gates were set on RAW264.7 macrophages due to their FSC/SSC characteristics. Data from 10000 cells were collected to reach a statistical significance. Statistical analysis was performed using the appropriate peak median. The shift of the median from untreated cells to PMA-treated cells was set to $100 \%$ activation and any inhibition was calculated proportionally.

\section{Statistical analysis}

Each experiment was performed at least three times, and statistical analysis was performed using the two-tailed Student's $t$-test. Otherwise, representative data are shown.

\section{Acknowledgements}

The work was supported by grants from Deutsche Forschungsgemeinschaft (BR999). We thank Sandra Christmann and Nadja Wallner for excellent technical assistance.

\section{References}

1. Savill J and Fadok V (2000) Corpse clearance defines the meaning of cell death. Nature 407: 784-788

2. Freire-de-Lima CG, Nascimento DO, Soares MB, Bozza PT, Castro-Faria-Neto HC, de Mello FG, DosReis GA and Lopes MF (2000) Uptake of apoptotic cells drives the growth of a pathogenic trypanosome in macrophages. Nature 403: 199-203

3. Voll RE, Herrmann M, Roth EA, Stach C, Kalden JR and Girkontaite I (1997) Immunosuppressive effects of apoptotic cells. Nature 390: 350-351

4. Lambeth JD (2004) NOX enzymes and the biology of reactive oxygen. Nat. Rev. Immunol. 4: 181-189

5. Inanami O, Johnson JL, McAdara JK, Benna JE, Faust LR, Newburger PE and Babior BM (1998) Activation of the leukocyte NADPH oxidase by phorbol ester requires the phosphorylation of p47PHOX on serine 303 or 304 . J. Biol. Chem. 273: 9539-9543

6. Bokoch GM and Diebold BA (2002) Current molecular models for NADPH oxidase regulation by Rac GTPase. Blood 100: 2692-2696

7. Larsen EC, DiGennaro JA, Saito N, Mehta S, Loegering DJ, Mazurkiewicz JE and Lennartz MR (2000) Differential requirement for classic and novel PKC isoforms in respiratory burst and phagocytosis in RAW 264.7 cells. J. Immunol. 165: 2809-2817

8. Li Q, Subbulakshmi V, Fields AP, Murray NR and Cathcart MK (1999) Protein kinase calpha regulates human monocyte 0-2 production and low density lipoprotein lipid oxidation. J. Biol. Chem. 274: 3764-3771

9. von Knethen A, Tautenhahn A, Link H, Lindemann D and Brune B (2005) Activation-induced depletion of protein kinase C\{alpha\} provokes desensitization of monocytes/macrophages in sepsis. J. Immunol. 174: 4960-4965

10. von Knethen A and Brune B (2003) PPARgamma - an important regulator of monocyte/macrophage function. Arch. Immunol. Ther. Exp. (Warsz) 51: 219-226 
11. Zhang $X$ and Young HA (2002) PPAR and immune system - what do we know? Int. Immunopharmacol. 2: 1029-1044

12. Daynes RA and Jones DC (2002) Emerging roles of PPARs in inflammation and immunity. Nat. Rev. Immunol. 2: 748-759

13. Chung SW, Kang BY, Kim SH, Pak YK, Cho D, Trinchieri G and Kim TS (2000) Oxidized low density lipoprotein inhibits interleukin-12 production in lipopolysaccharide-activated mouse macrophages via direct interactions between peroxisome proliferator-activated receptor-gamma and nuclear factor-kappa B. J. Biol. Chem. 275: 32681-32687

14. Holloway AF, Rao S and Shannon MF (2002) Regulation of cytokine gene transcription in the immune system. Mol. Immunol. 38: 567-580

15. Cvetanovic M and Ucker DS (2004) Innate immune discrimination of apoptotic cells: repression of proinflammatory macrophage transcription is coupled directly to specific recognition. J. Immunol. 172: 880-889

16. Cocco RE and Ucker DS (2001) Distinct modes of macrophage recognition for apoptotic and necrotic cells are not specified exclusively by phosphatidylserine exposure. Mol. Biol. Cell 12: 919-930

17. Savill J, Dransfield I, Gregory C and Haslett C (2002) A blast from the past: clearance of apoptotic cells regulates immune responses. Nat. Rev. Immunol. 2: $965-975$

18. Fadok VA, Bratton DL, Konowal A, Freed PW, Westcott JY and Henson PM (1998) Macrophages that have ingested apoptotic cells in vitro inhibit proinflammatory cytokine production through autocrine/paracrine mechanisms involving TGF-beta, PGE2, and PAF. J. Clin. Invest. 101: 890-898

19. Maasch C, Wagner S, Lindschau C, Alexander G, Buchner K, Gollasch M, Luft $\mathrm{FC}$ and $\mathrm{Haller} \mathrm{H}$ (2000) Protein kinase calpha targeting is regulated by temporal and spatial changes in intracellular free calcium concentration $[\mathrm{Ca}(2+)](\mathrm{i})$. FASEB J. 14: 1653-1663

20. Serinkan BF, Gambelli F, Potapovich Al, Babu H, Giuseppe MD, Ortiz LA, Fabisiak JP and Kagan VE (2005) Apoptotic cells quench reactive oxygen and nitrogen species and modulate TNF-alpha/TGF-beta1 balance in activated macrophages: involvement of phosphatidylserine-dependent and -independent pathways. Cell Death Differ. 8: 1141-1144

21. Feng J, Han J, Pearce SFA, Silverstein RL, Gotto Jr AM, Hajjar DP and Nicholson AC (2000) Induction of CD36 expression by oxidized LDL and IL-4 by a common signaling pathway dependent on protein kinase $C$ and PPARI\{gammal\}. J. Lipid Res. 41: 688-696

22. Kagan VE, Gleiss B, Tyurina YY, Tyurin VA, Elenstrom-Magnusson C, Liu SX, Serinkan FB, Arroyo A, Chandra J, Orrenius S and Fadeel B (2002) A role for oxidative stress in apoptosis: oxidation and externalization of phosphatidylserine is required for macrophage clearance of cells undergoing Fas-mediated apoptosis. J. Immunol. 169: 487-499

23. Lauber K, Bohn E, Krober SM, Xiao YJ, Blumenthal SG, Lindemann RK, Marini P, Wiedig C, Zobywalski A, Baksh S, Xu Y, Autenrieth IB, Schulze-Osthoff K, Belka C, Stuhler G and Wesselborg S (2003) Apoptotic cells induce migration of phagocytes via caspase-3-mediated release of a lipid attraction signal. Cell 113: $717-730$

24. Shiraki T, Kamiya N, Shiki S, Kodama TS, Kakizuka A and Jingami H (2005) Alpha,beta-unsaturated ketone is a core moiety of natural ligands for covalent binding to peroxisome proliferator-activated receptor gamma. J. Biol. Chem. 280: $14145-14153$
25. Mclntyre TM, Pontsler AV, Silva AR, St Hilaire A, Xu Y, Hinshaw JC, Zimmerman GA, Hama K, Aoki J, Arai H and Prestwich GD (2003) Identification of an intracellular receptor for lysophosphatidic acid (LPA): LPA is a transcellular PPARgamma agonist. Proc. Natl. Acad. Sci. USA 100: 131-136

26. Martin-Nizard F, Furman C, Delerive P, Kandoussi A, Fruchart JC, Staels B and Duriez $P$ (2002) Peroxisome proliferator-activated receptor activators inhibit oxidized low-density lipoprotein-induced endothelin-1 secretion in endothelial cells. J. Cardiovasc. Pharmacol. 40: 822-831

27. Wakino S, Kintscher U, Liu Z, Kim S, Yin F, Ohba M, Kuroki T, Schonthal AH, Hsueh WA and Law RE (2001) Peroxisome proliferator-activated receptor gamma ligands inhibit mitogenic induction of $\mathrm{p} 21 \mathrm{Cip} 1$ by modulating the protein kinase cdelta pathway in vascular smooth muscle cells. J. Biol. Chem. 276: 47650-47657

28. Patel H, Truant R, Rachubinski RA and Capone JP (2005) Activity and subcellular compartmentalization of peroxisome proliferator-activated receptor alpha are altered by the centrosome-associated protein CAP350. J. Cell Sci. 118: $175-186$

29. Von Knethen A and Brune B (2002) Activation of peroxisome proliferatoractivated receptor gamma by nitric oxide in monocytes/macrophages downregulates p47phox and attenuates the respiratory burst. J. Immunol. 169: 2619-2626

30. Ricote M, Li AC, Willson TM, Kelly CJ and Glass CK (1998) The peroxisome proliferator-activated receptor-gamma is a negative regulator of macrophage activation. Nature 391: 79-82

31. Cernuda-Morollon E, Rodriguez-Pascual F, Klatt P, Lamas S and Perez-Sala D (2002) PPAR agonists amplify iNOS expression while inhibiting NF-I\{kappal\}B: implications for mesangial cell. J. Am. Soc. Nephrol. 13: 2223-2231

32. Von Knethen A and Brune B (2001) Delayed activation of PPARgamma by LPS and IFN-gamma attenuates the oxidative burst in macrophages. FASEB J. 15: 535-544

33. Gurnell M, Wentworth JM, Agostini M, Adams M, Collingwood TN, Provenzano C, Browne PO, Rajanayagam O, Burris TP, Schwabe JW, Lazar MA and Chatterjee VK (2000) A dominant-negative peroxisome proliferator-activated receptor gamma (PPARgamma) mutant is a constitutive repressor and inhibits PPARgamma-mediated adipogenesis. J. Biol. Chem. 275: 5754-5759

34. Lindemann D, Bock M, Schweizer M and Rethwilm A (1997) Efficient pseudotyping of murine leukemia virus particles with chimeric human foamy virus envelope proteins. J. Virol. 71: 4815-4820

35. Pietschmann $T$, Heinkelein $M$, Heldmann $M$, Zentgraf $H$, Rethwilm $A$ and Lindemann D (1999) Foamy virus capsids require the cognate envelope protein for particle export. J. Virol. 73: 2613-2621

36. Soneoka Y, Cannon PM, Ramsdale EE, Griffiths JC, Romano G, Kingsman SM and Kingsman AJ (1995) A transient three-plasmid expression system for the production of high titer retroviral vectors. Nucl. Acids Res. 23: 628-633

37. Tautenhahn A, Brune B and von Knethen A (2003) Activation-induced PPARgamma expression sensitizes primary human $\mathrm{T}$ cells toward apoptosis J. Leukoc. Biol. 73: 665-672

38. Schulman IG, Shao G and Heyman RA (1998) Transactivation by retinoid X receptor-peroxisome proliferator-activated receptor gamma (PPARgamma) heterodimers: intermolecular synergy requires only the PPARgamma hormonedependent activation function. Mol. Cell. Biol. 18: 3483-3494 